\title{
The Relationship between Heat Stress, Survivability and Blood Composition of the Domestic Chicken ${ }^{1}$ )
}

\author{
Eitan Bogin, Yaakov Avidar, Volker Pech-Waffenschmidt, Yakir Doron, Bat-Ami Israeli and Erna Kevkhayev \\ Department of Biochemistry, Kimron Veterinary Institute, Tel Aviv University, School of Medicine, \\ Beit-Dagan, Israel
}

Summary: In order to better understand the metabolic changes leading to death which take place in the chicken during acute heat stress, the blood composition was determined in surviving and non-surviving chickens. The following blood analytes were determined: glucose, uric acid, serum total proteins, inorganic phosphate, total and ionized calcium, sodium, potassium, triiodothyronine, thyroxine. The haematocrit, erythrocyte creatine kinase (total and the isoenzymes) and haemoglobin fractions were also measured. Blood was taken from the wing vein before and after heat stress.

Eight-week-old "Anak 2000" broilers were kept in a climate chamber at $24{ }^{\circ} \mathrm{C} / 40 \%$ relative humidity during a 14hour day, and at $20^{\circ} \mathrm{C} / 40 \%$ relative humidity during a 10-hour night. The birds were subjected to heat stress by exposing them to $40^{\circ} \mathrm{C} / 30 \%$ relative humidity for 3 hours.

Significant differences between heat-stressed surviving and non-surviving chickens were seen in the blood levels of glucose, uric acid, total and ionized calcium, potassium, triiodothyronine, erythrocyte creatine kinase (total and isoenzymes). Differences were also seen in the levels and ratio of the 2 haemoglobin fractions.

The significance of these changes, and their potential use as markers for heat resistance is discussed.

\section{Introduction}

Permanent and acute heat exposure are among the stress factors affecting the metabolism of men and animals. Ambient temperatures exceeding the thermoneutral range lead to an elevated core temperature, leading to a number of responses, which result in the neutralisation of metabolic changes on one hand, and reduction of the body temperature on the other hand $(1-4)$.

Tissue response to hyperthermia is associated with injury to the vascular endothelium and consequent altered vascular permeability and oedema. An increase in the body temperature of any living creature concomitantly increases its metabolic rate. Above a certain thermal limit, denaturation of enzymes and precipitation of other proteins occur. In addition, "melting" of the lipid bilayers of cell membranes takes place, leading to changes in membrane characteristics and permeability, associated with leakage and loss of cellular constituents $(5,6)$.

Hyperthermia is manifested by a disturbance of the heat regulating mechanism of the body. Prolonged exposure to high environmental temperature causes peripheral blood vessels to dilate. Heat cramps may ensue, due to the subsequent loss of salt and deranged electrolyte balance $(7-13)$.

') This research was supported by a grant from GIARA - German-Israel Agricultural Research Association.
Among the clinical signs seen during hyperthermia are weakness, muscle tremors and collapse (11).

In the chicken, which lacks sweat glands, one adaptational response for cooling the body is panting, i. e. accelerating the breathing frequency. This leads to polypnea and a higher gas exchange rate, resulting in loss of carbon dioxide and enrichment of oxygen in the blood, thereby worsening the blood gas balance and leading to the development of respiratory alkalosis $(1,8,14)$.

Men and animals can adapt to varying concentrations of oxygen and carbon dioxide by the change of haemoglobin affinity for these gases. This affinity change is accomplished by a change in concentration of phosphorylated intermediates such as 2,3-bisphosphoglycerate or inositol phosphate, which complex with haemoglobin, leading to higher or lower binding affinity of oxygen and carbon dioxide $(6,15,16)$.

Animals behave and respond differently to heat stress. Furthermore, their structural composition and genetic characteristics contribute to their ability to resist heat stress. Knowing the factors that contribute to increased resistance is of great importance for understanding the pathological processes leading to death, and these factors are also possible markers for the determination and selection of heat-resistant animals.

Using clinical chemistry technology, the evaluation of blood composition can be a useful method for detecting 
changes due to heat stress. Blood composition changes as a result of metabolism, nutrition and cellular damage. Thus, blood levels of metabolites such as glucose, uric acid, minerals and proteins will be greatly affected by metabolism, nutrition and organ function. These changes can be measured by blood analysis and are related to the altered metabolism $(15,17)$.

It has been shown previously that a correlation exists between the degree of feathering of birds and the response to heat stress $(18,19)$, and that naked-neck chickens are more resistant to heat stress.

Even in chickens of the same age, size and breed, large variations were observed in their responses to heat stress, as evaluated by blood composition and behaviour. These differences suggest that genetic factors may contribute to heat resistance in chickens. Since these genetic factors are expressed in the biochemistry and metabolism of the organism, it should be possible to identify quantities affected by such factors, and use them to improve our understanding of the sequence of events leading to death from heat stress. Furthermore, we might use some of these quantities for evaluating and predicting the resistance of individual animals to heat stress, and by selecting such animals to produce a line of chickens with increased resistance to heat.

The objectives of the present study were to evaluate the biochemical changes associated with heat stress in chickens and their characteristics in surviving and nonsurviving animals.

\section{Materials and Methods}

Broilers

One hundred and fifty one-day-old Anak 2000 broilers were first grown in a brooder house for 5 weeks, after which they were transferred to cages, one bird per cage until the age of eight weeks (mean $2.50 \mathrm{~kg}$ in weight). Both males and females were used. One week prior to the experiment, the broilers were transferred to the climatic chamber and kept at $24^{\circ} \mathrm{C} / 40 \%$ humidity during a day of 14 hours duration, and at $20^{\circ} \mathrm{C} / 40 \%$ humidity during a night of 10 hours duration, for acclimatisation to the new environmental conditions. Food and water were given ad-libitum, and the quantities consumed were measured for each individual daily.

\section{Heat Shock}

The chickens were exposed to high environmental temperatures to cause acute heat shock. The temperature was gradually increased to $40{ }^{\circ} \mathrm{C} / 40 \%$ humidity during a period of two hours. The broilers were then kept for three hours under these conditions, after which the temperature was reduced to $25^{\circ} \mathrm{C} / 40 \%$ relative humidity. Following heat shock, the birds were divided into two groups:

(1) those surviving the heat shock and

(2) those not surviving the heat shock and dying within 24 hour after the heat shock.

Rectal temperatures were measured by a telethermometer model 46 TUC (Yellow Spring Instruments Co. Inc.).

\section{Blood withdrawal and analysis}

Blood samples were taken twice, prior to heat shock and during heat shock, three hours after reaching the target temperature. The blood was taken from the wing vein into two tubes, one for whole blood, containing lithium-heparin, and the other for serum. The heparinised blood was immediately put on ice and transferred to the laboratory. The non-heparinised blood was allowed to clot and the serum was separated by centrifugation at $600 \mathrm{~g}$ for 10 minutes.

\section{Blood and serum analysis}

The following analytes were determined int the serum: inorganic phosphorus (20), uric acid (21), total calcium (22), ionized calcium (23), potassium and sodium (23), total proteins (24), triiodothyronine $\left(\mathrm{T}_{3}\right)$ and thyroxine $\left(\mathrm{T}_{4}\right)$ using radioimmunoassay (Serono, Switzerland).

Whole blood was centrifuged at $600 \mathrm{~g}$, for $10 \mathrm{~min}$ to separate the plasma, and the erythrocytes were washed twice with saline by their resuspension and centrifugation in the cold. In the plasma, glucose was determined enzymatically (25). The erythrocytes were haemolysed in water, the membranes were precipitated by centrifugation at $10000 \mathrm{~g}$ for 10 minutes, and the supernatant was used for determination of haemoglobin (5), and total and isoenzyme levels of creatine kinase (ATP : creatine $\mathrm{N}$ phosphotransferase EC 2.7.3.2). Creatine kinase was measured spectrophotometrically (26); the isoenzymes (MM, MB, BB) were separated by electrophoresis (Helena Lab. U.S. A.) and their relative distribution, expressed in \% of total activity, was determined using a "Cliniscan II" densitometer (Helena Lab. U. S. A.).

Chemical and biochemical determinations were performed on a "Kone-Progress" (Finland) autoanalyser.

Blood haematocrit was determined following centrifugation.

Haemoglobin was separated by electrophoresis using Helena's kit and according to the manufacturer's instructions (Helena Lab. U.S. A.). The various fractions were quantitated using a "Cliniscan II" densitometer.

\section{Statistics}

Means, standard deviation, correlation coefficient and significance, were determined using the general linear model (GLM) procedure of the SAS program (27).

\section{Results}

Changes in the blood levels of various analytes, following heat stress, are given in table 1 . There were significant changes in blood analyte levels in both surviving and non-surviving groups. The changes can be divided into two: those showing similar patterns and those showing different patterns between the surviving and non-surviving groups.

Analytes changing in the same direction in both groups were inorganic phosphorus, total calcium and triiodothyronine (decreasing), and sodium, thyroxine and erythrocyte creatine kinase, isoenzymes $\mathrm{BB}$ and $\mathrm{MB}$ (increasing) and water consumption. Analytes changing in the opposite direction in the two groups were glucose, uric acid and erythrocyte total creatine kinase, ionized calcium, potassium and haemoglobin fractions.

The blood levels of glucose, uric acid, triiodothyronine and thyroxine in surviving and non-surviving chickens before and after heat stress are shown in table 2. In the non-surviving group the changes of serum levels of glu- 
Tab. 1 Pattern of changes and their significance following heat stress.

\begin{tabular}{|c|c|c|c|c|c|c|c|c|c|c|c|c|c|c|c|c|}
\hline \multirow[t]{2}{*}{ Group } & \multicolumn{9}{|c|}{ Serum } & \multicolumn{4}{|c|}{$\begin{array}{l}\text { Erythrocyte } \\
\text { creatine kinase }\end{array}$} & \multirow[t]{2}{*}{$\frac{\mathrm{Hb}-1}{\mathrm{Hb}-2}$} & \multirow[t]{2}{*}{ PCV } & \multirow{2}{*}{$\begin{array}{l}\text { Water } \\
\text { con- } \\
\text { sump } \\
\text { tion }\end{array}$} \\
\hline & $\begin{array}{l}\text { Glu- } \\
\text { cose }\end{array}$ & $\begin{array}{l}\text { Uric } \\
\text { acid }\end{array}$ & $\begin{array}{l}\text { Total } \\
\text { protein }\end{array}$ & $\begin{array}{l}\text { Phos- } \\
\text { phate }\end{array}$ & $\begin{array}{l}\mathrm{Ca} \\
\text { Total }\end{array}$ & $\mathrm{Ca}^{2+}$ & $\mathrm{K}^{+}$ & $\mathrm{Na}^{+} \mathrm{T} 3$ & T4 & Total & $\mathrm{BB}$ & MB & $\mathrm{MM}$ & & & \\
\hline $\begin{array}{l}\text { Survivor } \\
\text { Non- } \\
\text { survivor }\end{array}$ & $\uparrow^{*}$ & $\downarrow^{*}$ & $\begin{array}{l}= \\
=\end{array}$ & $l^{*}$ & $\downarrow^{*}$ & $\underset{1 *}{=}$ & $\underset{T^{*}}{=}$ & $\begin{array}{l}\uparrow * \\
\uparrow *\end{array} \quad \downarrow^{*}$ & $\uparrow *$ & $t^{*}$ & $\uparrow$ & $\uparrow *$ & $\downarrow$ & $\frac{1}{\dagger *}$ & $\begin{array}{l}= \\
=\end{array}$ & $\uparrow^{*}$ \\
\hline
\end{tabular}

* Significantly different from 0 time; $\mathrm{p}<0.01$.

$\mathrm{PCV}=$ Packed Corpuscular Volume, haematocrit.

Tab. 2 Blood levels of glucose, uric acid, T3 and T4 in the blood of surviving and non-surviving broilers before and during heat stress.

\begin{tabular}{|c|c|c|c|c|c|c|c|c|}
\hline & \multicolumn{8}{|l|}{ Analyte } \\
\hline & \multicolumn{2}{|c|}{ Glucose $(\mathrm{mmol} / \mathrm{l})$} & \multicolumn{2}{|c|}{ Uric acid $(\mu \mathrm{mol} / \mathrm{l})$} & \multicolumn{2}{|c|}{ T3 (nmol/l) } & \multicolumn{2}{|c|}{$\mathrm{T} 4$ (nmol/l) } \\
\hline & $\begin{array}{l}\text { Non- } \\
\text { Survivors }\end{array}$ & Survivors & $\begin{array}{l}\text { Non- } \\
\text { Survivors }\end{array}$ & Survivors & $\begin{array}{l}\text { Non- } \\
\text { Survivors }\end{array}$ & Survivors & $\begin{array}{l}\text { Non- } \\
\text { Survivors }\end{array}$ & Survivors \\
\hline \multicolumn{9}{|c|}{ Before heat stress } \\
\hline $\begin{array}{l}\bar{x} \\
\text { SE } \\
n\end{array}$ & $\begin{array}{l}12.71 \\
0.08 \\
80\end{array}$ & $\begin{array}{c}12.77 \\
0.08 \\
70\end{array}$ & $\begin{array}{r}397 \\
16 \\
80\end{array}$ & $\begin{array}{r}359 \\
16 \\
70\end{array}$ & $\begin{array}{l}3.72 \\
0.14 \\
25\end{array}$ & $\begin{array}{l}4.36 \\
0.35 \\
15\end{array}$ & $\begin{array}{r}86 \\
5 \\
25\end{array}$ & $\begin{array}{l}92 \\
10 \\
15\end{array}$ \\
\hline \multicolumn{9}{|c|}{ After heat stress } \\
\hline $\begin{array}{l}\bar{x} \\
\text { SE } \\
n\end{array}$ & $\begin{array}{l}11.55^{\mathrm{a}} \\
0.28 \\
80\end{array}$ & $\begin{array}{c}13.76^{\mathrm{a}, \mathrm{b}} \\
0.17 \\
70\end{array}$ & $\begin{array}{c}677^{a} \\
37 \\
80\end{array}$ & $\begin{array}{c}281^{a, b} \\
19 \\
70\end{array}$ & $\begin{array}{l}3.01^{a} \\
0.14 \\
25\end{array}$ & $\begin{array}{l}2.69^{a, b} \\
0.14 \\
15\end{array}$ & $\begin{array}{r}101^{a} \\
4 \\
25\end{array}$ & $\begin{array}{r}103 \\
5 \\
15\end{array}$ \\
\hline
\end{tabular}

a significance $(p<0.01)$ between levels before and after heat stress.

cose, uric acid, triiodothyronine and thyroxine were significantly $(p<0.01)$ different before and after heat stress. In the surviving group, except for thyroxine, the changes were also significantly $(p<0.01)$ different following heat stress. While the differences in blood levels between the surviving and non-surviving chickens before heat stress were not significant, they were significantly $(p<0.01)$ different (except for thyroxine), following heat stress (tab. 2). b significance $(p<0.01)$ between surviving and non-surviving chickens.

The blood levels of inorganic phosphate, total and ionized calcium, potassium and sodium in chickens before and after heat stress are shown in table 3 . Except for ionized calcium and potassium in the surviving group, the analytes measured showed significant changes following heat stress. There were significant differences between surviving and non-surviving chickens in the serum levels of potassium before heat stress and in the serum levels of inorganic phosphate,

Tab. 3 Levels of electrolytes in the blood of broilers before and after heat stress.

\begin{tabular}{|c|c|c|c|c|c|c|c|c|c|c|}
\hline & \multicolumn{10}{|l|}{ Analyte } \\
\hline & \multicolumn{2}{|c|}{$\begin{array}{l}\text { Inorganic phosphate } \\
(\mathrm{mmol} / \mathrm{l})\end{array}$} & \multicolumn{2}{|c|}{$\begin{array}{l}\text { Total calcium } \\
(\mathrm{mmol} / \mathrm{l})\end{array}$} & \multicolumn{2}{|c|}{$\begin{array}{l}\text { Ca, ionized } \\
(\mathrm{mmol} / \mathrm{l})\end{array}$} & \multicolumn{2}{|l|}{$\begin{array}{l}\text { Potassium } \\
(\mathrm{mmol} / \mathrm{l})\end{array}$} & \multicolumn{2}{|l|}{$\begin{array}{l}\text { Sodium } \\
(\mathrm{mmol} / \mathrm{l})\end{array}$} \\
\hline & $\begin{array}{l}\text { Non- } \\
\text { Survivors }\end{array}$ & Survivors & $\begin{array}{l}\text { Non- } \\
\text { Survivors }\end{array}$ & Survivors & $\begin{array}{l}\text { Non- } \\
\text { Survivors }\end{array}$ & Survivors & $\begin{array}{l}\text { Non- } \\
\text { Survivors }\end{array}$ & Survivors & $\begin{array}{l}\text { Non- } \\
\text { Survivors }\end{array}$ & Survivors \\
\hline \multicolumn{11}{|c|}{ Before heat stress } \\
\hline $\begin{array}{l}\bar{x} \\
\text { SE }\end{array}$ & $\begin{array}{l}2.11 \\
0.03\end{array}$ & $\begin{array}{l}2.07 \\
0.02\end{array}$ & $\begin{array}{l}2.53 \\
0.02\end{array}$ & $\begin{array}{l}2.53 \\
0.02\end{array}$ & $\begin{array}{l}1.15 \\
0.02\end{array}$ & $\begin{array}{l}1.09 \\
0.02\end{array}$ & $\begin{array}{l}6.38 \\
0.09\end{array}$ & $\begin{array}{l}6.18^{b} \\
0.07\end{array}$ & $\begin{array}{c}143.6 \\
0.27\end{array}$ & $\begin{array}{r}143.3 \\
0.3\end{array}$ \\
\hline \multicolumn{11}{|c|}{ After heat stress } \\
\hline $\begin{array}{l}\bar{x} \\
\text { SE }\end{array}$ & $\begin{array}{l}1.23^{\mathrm{a}} \\
0.04\end{array}$ & $\begin{array}{l}1.60^{a, b} \\
0.05\end{array}$ & $\begin{array}{l}2.35^{a} \\
0.02\end{array}$ & $\begin{array}{l}2.45^{\mathrm{a}, \mathrm{b}} \\
0.02\end{array}$ & $\begin{array}{l}1.01^{\mathrm{a}} \\
0.01\end{array}$ & $\begin{array}{l}1.10^{b} \\
0.01\end{array}$ & $\begin{array}{l}6.98^{a} \\
0.07\end{array}$ & $\begin{array}{l}6.12^{\mathrm{a}} \\
0.07\end{array}$ & $\begin{array}{c}146.3^{\mathrm{a}} \\
0.5\end{array}$ & $\begin{array}{c}146.9^{\mathrm{a}} \\
0.4\end{array}$ \\
\hline
\end{tabular}

$\mathrm{n}=70-80$

a significantly different $(p<0.01)$ between levels before and after heat stress. surviving chickens. 
Tab. 4 Total creatine kinase activity and the activities of creatine kinase isoenzymes, and their relative distribution in erythrocytes in surviving and non-surviving broilers before and during heat stress.

\begin{tabular}{|c|c|c|c|c|c|c|c|c|}
\hline & \multirow{2}{*}{\multicolumn{2}{|c|}{$\begin{array}{l}\text { Total } \\
\text { creatine kinase } \\
(\mathrm{U} / \mathrm{mg} \mathrm{Hb})\end{array}$}} & \multicolumn{6}{|c|}{ Creatine kinase isoenzymes } \\
\hline & & & \multicolumn{2}{|l|}{$\mathrm{BB}(\%)$} & \multicolumn{2}{|l|}{$\mathrm{MB}(\%)$} & \multicolumn{2}{|l|}{$\mathrm{MM}(\%)$} \\
\hline & $\begin{array}{l}\text { Non- } \\
\text { Survivors }\end{array}$ & Survivors & $\begin{array}{l}\text { Non- } \\
\text { Survivors }\end{array}$ & Survivors & $\begin{array}{l}\text { Non- } \\
\text { Survivors }\end{array}$ & Survivors & $\begin{array}{l}\text { Non- } \\
\text { Survivors }\end{array}$ & Survivors \\
\hline \multicolumn{9}{|c|}{ Before heat stress } \\
\hline $\begin{array}{l}\bar{x} \\
S E\end{array}$ & $\begin{array}{r}25.1 \\
2.5\end{array}$ & $\begin{array}{r}30.6 \\
4.6\end{array}$ & $\begin{array}{l}2.91 \\
0.27\end{array}$ & $\begin{array}{l}2.35 \\
0.17\end{array}$ & $\begin{array}{r}15.1 \\
1.1\end{array}$ & $\begin{array}{r}12.9 \\
1.2\end{array}$ & $\begin{array}{r}82.0 \\
1.2\end{array}$ & $\begin{array}{r}85.2 \\
1.2\end{array}$ \\
\hline \multicolumn{9}{|c|}{ After heat stress } \\
\hline $\begin{array}{l}\bar{x} \\
S E\end{array}$ & $\begin{array}{c}15.2^{\mathrm{a}} \\
2.2\end{array}$ & $\begin{array}{c}37.3^{b} \\
4.7\end{array}$ & $\begin{array}{r}4.84^{\mathrm{a}} \\
0.57\end{array}$ & $\begin{array}{l}2.66^{\mathrm{b}} \\
0.17\end{array}$ & $\begin{array}{c}22.9^{\mathrm{a}} \\
2.0\end{array}$ & $\begin{array}{c}14.2^{\mathrm{b}} \\
3.0^{\circ}\end{array}$ & $\begin{array}{c}72.3^{\mathrm{a}} \\
2.3\end{array}$ & $\begin{array}{c}83.1^{b} \\
3.0\end{array}$ \\
\hline
\end{tabular}

$\mathrm{n}=7-24$

a significance levels $(p<0.01)$ between levels before and after heat stress.
${ }^{b}$ significance levels $(p<0.01)$ between surviving and non-surviving chickens.

Tab. 5 Rate of water consumption and haematocrit of survivors and non-surviving broilers before and during heat stress.

\begin{tabular}{|c|c|c|c|c|c|c|}
\hline & \multicolumn{6}{|l|}{ Quantity } \\
\hline & \multicolumn{2}{|c|}{ Water consumed $(\mathrm{ml} / \mathrm{h})$} & \multicolumn{2}{|l|}{ Haematocrit } & \multicolumn{2}{|c|}{ Body temperature $\left({ }^{\circ} \mathrm{C}\right)$} \\
\hline & Non-Survivors & Survivors & Non-Survivors & Survivors & Non-Survivors & Survivors \\
\hline \multicolumn{7}{|c|}{ Before heat stress } \\
\hline$\overline{\mathbf{x}}$ & 24.3 & 26.0 & 0.315 & 0.303 & 40.8 & 40.7 \\
\hline SE & 2.3 & 3.8 & 0.004 & 0.004 & 0.2 & 0.2 \\
\hline $\mathrm{n}$ & 25 & 15 & 80 & 70 & 80 & 70 \\
\hline \multicolumn{7}{|c|}{ During/after heat stress } \\
\hline$\overline{\mathrm{x}}$ & $54.8^{\mathrm{a}}$ & $71.7^{\mathrm{a}, \mathrm{b}}$ & 0.309 & 0.294 & 43.2 & 42.7 \\
\hline SE & 6.8 & 13.4 & 0.004 & 0.004 & 0.4 & 0.4 \\
\hline n & 25 & 15 & 80 & 70 & 80 & 70 \\
\hline
\end{tabular}

a significance $(p<0.01)$ between levels prior to and after heat stress.

total and ionized calcium and potassium after heat stress (tab. 3).

The levels of total creatine kinase and its isoenzymes from the erythrocytes of surviving and non-surviving chickens before and after heat stress are shown in table 4. There were significant $(p<0.01)$ changes in the creatine kinase activity (total and isoenzymatic) following heat stress only in the non-surviving chickens. Although there were no significant differences between the surviving and the non-surviving before heat stress, there were significant differences in the erythrocyte levels of creatine kinase activity between these groups following heat stress (tab. 4).

The amount of water consumed, the blood haematocrit of surviving and non-surviving chickens and cloacal temperatures before and after heat stress are depicted in table 5. As seen and expected, heat stress caused the chickens to increase their water consumption, significantly more in the surviving group. There were no significant differences in the haematocrit between the groups either before or after heat stress (tab. 5). b significance $(p<0.01)$ between surviving and non-surviving chickens.

The relative distribution of the two haemoglobin fractions before and after heat stress are shown in table 6 and figure 1. Following electrophoretic separation, 2 main peaks were seen: peak 1 , in the region of human haemoglobin $C$ and peak 2 in the region of human haemoglobin $\mathrm{S}$. The relative distribution and consequently the ratios between the two fractions were significantly $(p<0.01)$ different between the surviving and the nonsurviving chicken groups following heat stress. While the ratio between the two fractions changed slightly in the surviving group, it was significantly higher in the

Tab. 6 The relationship between haemoglobin composition and survivability of broilers subjected to heat stress.

\begin{tabular}{|c|c|c|c|}
\hline & \multicolumn{2}{|c|}{ Haemoglobin (\%) } & \multirow{2}{*}{$\frac{\text { Peak } 1}{\text { Peak } 2}$} \\
\hline & Peak 1 & Peak 2 & \\
\hline $\begin{array}{l}\text { Surviving } \\
\text { Non-Surviving }\end{array}$ & $\begin{array}{l}55.5 \pm 5.8 \\
69.8 \pm 7.1\end{array}$ & $\begin{array}{l}44.5 \pm 4.8 \\
30.2 \pm 3.2\end{array}$ & $\begin{array}{l}1.25 \pm 0.11 \\
2.31 \pm 0.28^{\mathrm{a}}\end{array}$ \\
\hline
\end{tabular}

$\mathrm{n}=9$

a significance $(p<0.01$ ) between levels before and after heat stress. 


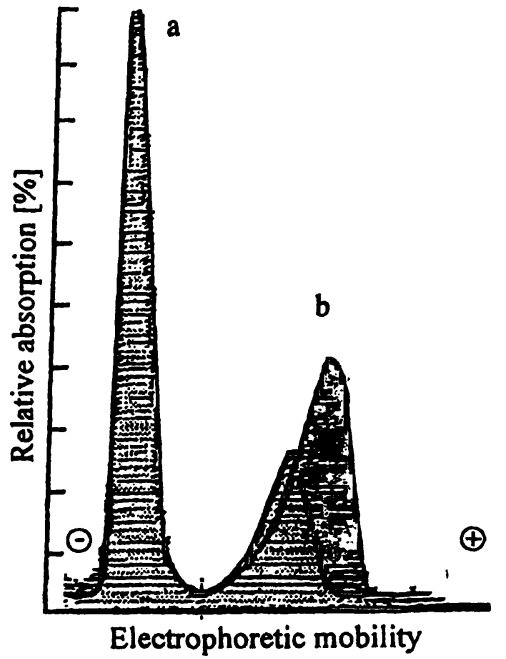

Fig. 1 Haemoglobin fractions separated by electrophoresis from surviving and non-surviving broilers following heat stress (relative distribution)

a: peak in the haemoglobin $C$ region

b: peaks in the haemoglobin $\mathrm{S}$ region

自 non-surviving 口 surviving

non-surviving group, resulting from an increase of peak 1 and a decrease of peak 2 , so that the mean ratio changed from 1.25 to 2.31 .

The correlations between the various blood analytes are shown in table 7. Significant, high correlations (above 0.9000) were seen between uric acid and erythrocyte creatine kinase isoenzyme, and also between glucose and uric acid. Lower correlations were seen between glucose and ionized calcium $(r=0.8427)$, glucose and inorganic phosphate $(\mathrm{r}=-0.8685)$, triiodothyronine and glucose $(r=0.7670)$ and inorganic phosphate and total calcium $(r=0.6851)$.

Tab. 7 Correlation between blood analytes from broilers under heat stress.

\begin{tabular}{lr}
\hline Analytes & \multicolumn{1}{c}{$r(\bar{x} \pm$ SEM; $n)$} \\
\hline Glucose - uric acid & $-0.9010 \pm 0.089 ; 32$ \\
Glucose - ionized calcium & $0.8427 \pm 0.011 ; 24$ \\
Glucose - inorganic phosphate & $-0.8685 \pm 0.012 ; 32$ \\
Uric acid - creatine kinase BB & $0.9460 \pm 0.010 ; 18$ \\
Uric acid - creatine kinase MB & $0.9560 \pm 0.014 ; 18$ \\
Uric acid - creatine kinase MM & $-0.9648 \pm 0.013 ; 18$ \\
Inorganic phosphate - total calcium & $0.6851 \pm 0.080 ; 34$ \\
$T_{3}$ - glucose & $0.7670 \pm 0.091 ; 30$ \\
\hline
\end{tabular}

$\mathrm{p}<0.01$

\section{Discussion}

Heat stress and hyperthemia lead to panting and consequent respiratory alkalosis, with extreme metabolic changes resulting in death.

The objectives of the present study were to:

(1) better understand the sequence of events and metabolic problems leading to the death of the chickens caused by heat stress,
(2) search for biochemical quantities which correlate well with the ability of the chicken to survive heat stress and hopefully use them as markers for the evaluation of heat stress survivability.

With these objectives in mind a wide range of biochemical analytes representing the various aspects of metabolism, nutriton, renal, liver and cardiac functions were determined.

Table 1 shows the blood levels of various analytes that change in the same direction in both surviving and nonsurviving groups. These analytes have no potential as markers of survivability, unless the changes vary greatly in their intensity between the two groups. On the other hand, analytes in which the changes occur in opposite directions, have a greater potential both in aiding the understanding of the mechanism leading to the death of the chicken, and as markers characterising the ability to survive heat stress.

Among the analytes showing such a pattern are glucose which was elevated in the surviving group and lowered in the non-surviving group. The lower glucose levels seen in the non-surviving chickens can be explained by possible reduced gluconeogenic activity, due to the accumulation of organic acids in response to the alkalosis. Alternatively, the observed decrease in gluconeogenesis may be due to its decrease in the kidney. The increased blood uric acid is evidence of an affect on the kidneys, indicating renal failure.

Another blood analyte showing a different pattern between surviving and non-surviving chickens (following heat stress), was uric acid, which decreased in the surviving and increased in the non-surviving groups. The significant increase of uric acid, the main end product of nitrogen metabolism in chickens $(6,15,16)$, could indicate renal insufficiency in the non-surviving chicken, which could be secondary to heart function insufficiency $(5,15,17)$.

The degree of renal insufficiency is not clear, since inorganic phosphate levels which normally increase in massive renal failure $(5,15,17)$, decreased in this case for reasons to be discussed later. Potassium, which also increases in terminal renal failure $(5,15,17)$, was increased in the non-surviving chicken. The reason for the small decrease in the blood level of uric acid in the surviving group could be either dilution of the blood because of the increased water uptake, or enhanced removal of uric acid from the blood due to faster blood circulation in the kidney.

The ratio of the two analytes - glucose and uric acid can serve as a quantity for the evaluation of the degree of stress and consequently the sensitivity of the chickens to heat stress and their ability to survive it. While the ratios between the two analytes in both groups were 
identical (34.5) before heat stress, they were much lower (18.3) in the non-surviving and higher (52.5) in the surviving chickens following heat stress. This ratio seems to be a more sensitive quantity, having a larger scale and being more accurate because of its dependence on two measurements.

Of interest is the quantity "creatine kinase activity" in the erythrocyte haemolysate. Since the role of this enzyme in the erythrocytes is not clear, it is possible that the activity seen is either of an enzyme related to the erythrocyte skeleton or to any other activity involved in the generation of adenosine triphosphate which will produce a signal of creatine kinase activity. The last possibility may fit with the observation that inorganic phosphate in the serum decreased during heat stress (tab. 3) and probably entered the erythrocytes (18).

In a previous study, we showed that total phosphates in the erythrocytes increased following heat stress (18). Furthermore, the role and importance of phosphorylated intermediates in the erythrocytes for the regulation of haemoglobin affinity to oxygen and carbon dioxide is well established. These intermediates are 2,3-bisphosphoglycerate in mammals and inositol phosphate in birds. The main extracellular buffer system consists of carbonates, while a major intracellular buffer consists of phosphates. While the regulation of the carbonates can be achieved by respiration and kidney excretion, the intracellular buffering strength can be adapted by mobilisation of phosphates into and out of the cells $(5,15$, 18). It is therefore reasonable that phosphates entering the erythrocytes not only contribute to the buffering of the cytoplasm, but also to the regulation of the haemoglobin, which during panting has to deal more effectively with the high oxygen and low carbon dioxide levels; this latter regulation occurs by an increase in the level of phosphates in the red blood cells $(5,15,18)$.

Thus, although it has not been proven, it is possible that some of these creatine kinase activities observed in the erythrocyte haemolysate originated from phosphorylated intermediates in the cells. Indeed, changes in the relative distribution of the various "isoenzymatic" peaks correlate with the survivability of chickens to heat stress.

The creatine kinase activity was further characterised. Heat treatment at $70^{\circ} \mathrm{C}$ for 1 minute completely abolished this activity. Furthermore, dialysis of the haemolysate for 24 hours (exclusion pore size of 25000 ) did not abolish the activity. The data suggest that this creatine kinase activity is associated with a large molecular mass, heat-sensitive molecule and that it is not dialysable, either because it is large, or because it is bound to another large molecule.

Measurement and characterisation of the haemoglobin revealed two fractions that are different from the normal haemoglobin fractions known in mammals. The avian haemoglobin fractions migrated in an electrophoretic field to regions where the pathological human haemoglobin $\mathrm{S}$ and $\mathrm{C}$ are found. Of interest was the observation that the relative distribution, and consequently, the ratio between the two haemoglobin peaks changed following heat stress, with a lower ratio in the surviving group and an elevated ratio in the non-surviving chickens. This phenomenon supports the theory that heat stress leads to changes of the haemoglobin, changes which are different between the surviving and non-surviving chickens exposed to heat stress.

The significance of the changes in the levels of creatine kinase activity and the haemoglobin fractions in relation to heat stress is not clear. Furthermore, it is not known whether any relationship exists between these changes. The fact that both changes are triggered by heat stress, and are highly correlated with survivability, suggests a relationship and a possible role in the mechanism of the response to and protection from heat stress.

Non-surviving chickens drank significantly less water than the surviving ones. It is of interest that despite the fact that water consumption was 2-3 times greater, it did not affect the haematocrit. This could be explained by the greater water loss by evaporation through the lungs, by the water loss in the faeces which became very watery during the heat stress, and by the very big water accumulation in the crop.

In conclusion, the present study shows some highly significant changes, which correlate highly with heat stress survivability. These traits relate to the ability to overcome the metabolic stress leading to renal insufficiency, and to maintain normal levels of glucose, ionized calcium and phosphorus. It seems that the surviving birds are more capable of coping the loss of carbon dioxide and high oxygen levels caused by hyperventilation, by manipulating the haemoglobin affinity for these gases; this may be related to the change in the haemoglobin subgroups and in those phosphate intermediates controlled or expressed by the creatine kinase activity in the erythrocytes.

This adaptability to acute hyperthermia could be a genetic characteristic. Therefore, those blood properties that are highly correlated with the ability to withstand heat stress may serve as genetic markers for the selection and development of a chicken more resistant to heat stress. 


\section{References}

1. Van Kampen M. Some aspects of thermoregulation in the White Leghorn fowl. Int J Biometeor 1971; 15:244-246. SAS Institute Inc. (1985).

2. Polonis $A$. The influence of the thermal factor on some biochemical indices of chicken blood plasma. Pol Arch Veter 1982; 23:49-56.

3. Kohne HJ, Jones JE. Changes in plasma electrolytes, acid-base balance and other physiological parameters of adult female turkeys under conditions of acute hyperthermia. Poultry Sci 1975a; 54:2034-8.

4. Ward MA, Peterson RA. The effect of heat exposure on plasma uric acid, lactate dehydrogenase, chloride, total protein and zinc of the broiler. Poultry Sci 1973; 52:1671-3.

5. Tietz NW. Fundamentals of clinical chemistry. Philadelphia, London, Toronto: W. B. Saunders Company, 1970:267.

6. Lehninger A. Biochemistry. 2nd ed. New York: Worth Publishers Inc, 1975

7. Whittow GC, Regulation of body temperature. In: Sturkie PD, editor. 4th ed. New York, Heidelberg, Tokyo: Springer Verlag 1986:221-52.

8. Bowen SJ, Washburn KW. Genetics of heat tolerance in Japanese quail. Poultry Sci 1984; 63:430-5.

9. Van Handel-Hruska JM, Wegner TN, Nordstrom JO. Avian cardio-vascular responses following high environmental temperature acclimation [abstract]. Fed Am Soc Exp Biol 1977; 36:524.

10. Bogin E, Weisman Y, Friedman, Y. Effect of heat shock on the biochemical composition of chicken blood. Ref Vet 1981; 38:(3) $98-104$.

11. Odom TW, Harrison PC, Bottje WJ. Effects of thermal induced respiratory alkalosis on blood ionized calcium levels in the domestic hen. Poultry Sci 1985; 3:570-3.

12. Arad Z, Marder J, Eylath U. Serum electrolytes and enzyme responses to heat stress and dehydration in the fowl. Comp Biochem Physiol 1983, 74A:449-53.

13. Arad Z, Marder J. Acid base regulation during thermal panting in the fowl: comparison between breeds. Comp Biochem Physiol 1983, 74A:125-30.

14. Darre MJ, Odom TW, Harrison PC, Staten FE. Time course of change in respiratory rate, blood $\mathrm{pH}$ and blood $\mathrm{pCO}_{2}$ of $\mathrm{SCWL}$ hens during heat stress. Poultry Sci 1980; 59:1598-605.

15. Kaneko JJ. Clinical biochemistry of domestic animals. London, Toronto, San Francisco: Acad Press, 1989.
16. White A, Handler P, Smith EL, Hill RL, Lehman IR. Principles of biochemistry. 6th ed. New York: McGraw-Hill Book Co, 1978.

17. Bogin E. Handbook of animal clinical chemistry. New York: Kodak Publ USA, 1992.

18. Pech-Waffenschmidt V, Bogin E, Avidar Y, Horst P. Metabolic and biochemical changes during heat stress in relation to the feathering degree of the domestic hen. Avian Pathol, 1995; 24:33-44.

19. Horst P. Effects of genotype $x$ environment interactions on efficiency of improvement of egg production. In: Hill WG, Manson JM, Hewlett D, editors. Poultry genetics and breeding. Edinburgh: Longman-Harlow, 1985:147-56.

20. Wang J, Chin CC, Osaki S. Optimization of the phosphorus UV reagent [abstract]. Clin Chem 1983; 29:1255.

21. Fossati P, Prencipe L, Berti G. Use of 3,5-dichloro-2-hydroxy benzenesulfonic acid 4-aminophenazone chromogenic system in direct enzymatic assay of uric acid in serum and urine. Clin Chem 1980; 26:227-31.

22. Bauer PJ. Affinity and stoichiometry of calcium binding by Arsenazo III. Anal Biochem 1981; 110:61-72.

23. Lewenstam A, Maj-Zurawska M, Hulanicki A. Application of ion selective electrodes in clinical analysis. Electroanalysis. $1991 ; 3: 727-34$.

24. Doumas B. Standards for total serum protein assays. A collaborative study. Clin Chem 1975; 21:1159-66.

25. Bonder RJL, Mead DC. Evaluation of glucose-6-phosphate dehydrogenase from Leuconostoc mesenteroides in the hexokinase method for determining glucose in serum. Clin Chem 1974, 20:586-90.

26. Szasz G, Walderstrom J, Gruber W. Creatine kinase in serum. Inhibition by endogenous polyvalent cation and effect of chelators on the activity and stability of some components. Clin Chem 1979; 25:446-52.

27. SAS Institute Inc. SAS user's guide: statistics, SAS Institute Inc. Carry, NC, NY, 1985.

Received October 19, 1995/January 30, 1996

Corresponding author: Prof. Dr. E. Bogin, Dept. of Biochemistry, Kimron Veterinary Institute, Tel Aviv University, School of Medicine, PO Box 12, Beit-Dagan, 50250 Israel 


$$
\text { . }
$$

